Original article

\title{
Treatment seeking behavior and level of treatment among brick kiln workers: A Study in Azamgarh District, Uttar Pradesh
}

\author{
Kumar Parimal Shrestha ${ }^{\text {a, *, }}$, Harihar Sahoo ${ }^{\text {b }}$, Mrinmoy Pratim Bharadwaz ${ }^{\text {a }}$

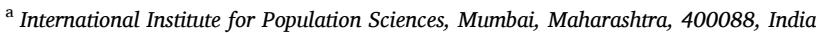 \\ ${ }^{\mathrm{b}}$ Department of Development Studies, International Institute for Population Sciences, Mumbai, Maharashtra, 400088, India
}

\section{A R T I C L E I N F O}

\section{Keywords:}

Brick kiln

India

Level of treatment

Treatment seeking

Occupational morbidity

\begin{abstract}
A B S T R A C T
Background: Brick kiln industries are usually located at remote locations due to which labors feel difficulties to even fulfill their basic needs. They are bound to buy their requirements from assigned suppliers. In order to receive treatment, labors don't find much of the options to choose. This study tends to examine the treatment seeking behavior and their level of treatment among brick kiln workers.

Method: A structured interview and in-depth interviews were used for data. Data entry was done in SPSS version 23. Data was analyzed using STATA version 15.

Result: Total of 450 respondents, $82.7 \%$ suffered from musculoskeletal disorder, and 53.8\% suffered from respiratory disease and similar number of molders were suffering from aforementioned diseases. More than $30 \%$ of workers suffered from eye disease and skin disease in 36-50 years of age category. In the study, 95\% workers were suffering from occupational morbidity. Out of which $92.5 \%$ reported utilization of outpatient care, whereas, $7 \%$ of non-users stated, primary reason for not using health care services were, low financial support, unawareness of health centers, tight working hours.

Conclusion: The prevalence of occupational morbidity is high whereas, treatment seeking among workers are not satisfying. Treatment seeking among labors is found to be delayed and above all, labors are highly ignorant about symptoms. Due to low income, low education and skills, deprived workers are considered for low grade and poorly paid jobs in the kilns where they are victimized by their employer and ill treatment regarding salary and wages were also observed.
\end{abstract}

\section{Introduction}

The health status of a community or a population is reflected by the levels of morbidity and the treatment seeking behavior of its member. This study emphasize on the treatment seeking behavior and level of treatment of diseases among brick kiln workers. Some of the past studies conducted shows that public preferences for outpatient care services were very low (14\%). A majority of household reported to seek treatment from private hospitals (82\%) for outpatient. ${ }^{1,2}$ In another study on health services in slums of Mumbai shows an overall decrease in the expenditure on health which indicates somewhere the negligence of seeking health treatment. ${ }^{2}$ The major part of expenditure was in private hospitals than government hospitals and health care centers. Another study shows that in Dharavi slums of Mumbai the overall the utilization of urban health centers were low compared to private health care centers. ${ }^{3}$ Private hospitals and doctors are preferred by laborers for the treatment because of their easy availability, better treatment facility, convenient time slots and proper attention towards their issues. The prime reason for workers those who preferred to visit private health care centers for treatment compared to urban health centers (UHC) was better quality of services and competent staffs for service providing. Another study on out-patient care utilization revealed that $77 \%$ surveyed workers utilize private health care services. Degraded quality, services and accessibility of the public sector were considered to be the primary cause for the utilization of private health care services. ${ }^{4}$ Babu et al. in their study revealed that due to the unavailability of the government health care facilities within the easy reach of workers, private health care centers are preferred as they are easily accessible for them. In some parts of the country such as Delhi situation varies and are Government health care centers are of easy access for most of the workers but due to their migration they are unaware of facilities available nearby and end up reaching private health care centers, as they have better

\footnotetext{
* Corresponding author.

E-mail address: parimalshrestha007@gmail.com (K.P. Shrestha).
} 
advertisements. ${ }^{1}$ Most of the times when any member of family falls sick, first option to render workers mind is private practitioner (often unqualified). The workers those who were even aware of government health care don't opt to visit there for treatment seeking owing to poor health care services and involved indirect cost. The migrant workers priorities their health care treatment seeking towards private health care centers even risking their daily wages while being absent on work in order to receive better treatment as there is a negative pre-conceived notion for government health care institutions. ${ }^{1}$ A study in Tamil Nadu among brick kiln workers showed that $60 \%$ of workers having symptoms of respiratory illness look for private health care over government health care. ${ }^{5}$ Overall, $20 \%$ of workers relied on government health care institutions irrespective of long distance, interrupted transportation and rigorous working hours. Delay in health care seeking among workers for prevailing morbidity conditions, among which only $25 \%$ seek treatment on time. The study also explored that the duration of stay over 9 months was found to be significantly associated with treatment seeking where prime reason for not seeking treatment was not considering the symptoms severity level for seeking treatment (47.6\%) with adjoining work pressure (44\%). Long distance and interrupted transportation to health centers $(10 \%)$ and financial restrictions $(8.6 \%)$ also acted as the obstacle for them in health care seeking. ${ }^{1}$ Another study revealed $78.8 \%$ of migrant children faced at least one episodic illness during a year, whereas, $71 \%$ took treatment and $61 \%$ among them incurred out-of-pocket expenditure by. ${ }^{6}$ Migrant workers primarily relied on private doctors (often unqualified) for the treatment of episodic illness. Elaborately $73 \%$ cited their primary source of treatment as private doctors, $11 \%$ as medical shops and $4 \%$ as home remedies. ${ }^{6}$ The objective of the study was to explore treatment seeking behavior and economic burden on expenditure on treatment of disease.

\section{Materials and methods}

In the present research, the methodology is designed as ample selection of the study area and population, sampling techniques and sample size survey instrument, the construction of the questionnaire data collection procedure, data processing and analysis are further stated.

\subsection{Selection of the study area and population}

Brick industry is one of the emerging industry in India which has estimated annual production of approximately 250-300 billion bricks per annum. It is estimated to have around 100,000 brick kilns in India which makes the country the second largest global producer of clay fired bricks and accounts for the $10 \%$ of the global production. There are about more than 18,000 recorded brick kiln in Uttar Pradesh (Uttar Pradesh Pollution Control Board, 2017). In present study, Azamgarh district had been identified as the study area comprising of 647 brick kilns, highest in a district, in whole country.

\subsection{Sampling techniques and sample size}

There are about more than 18,000 recorded brick kiln in Uttar Pradesh (Uttar Pradesh Pollution Control Board, 2017). Out of which Azamgarh consists of 647 registered brick kilns. Ten brick kilns will be selected systematically based on Probability Proportional to Size (PPS). Sample size was determined systematically after the exhaustive list of workers from each occupational category were prepared. Fifteen respondents from each of the occupational category were selected viz. molder, loader and firemen. Therefore, 15 labors from each category i.e molders, loaders and firemen were selected. Further, from each kiln (15 x 3) 45 respondents were selected. Thus, 10 systematically selected brick kilns based on Probability Proportional to Size (PPS) resulted a total of 450 respondents for the current study.

\subsection{Survey instruments}

Interview schedule were used as the tool for data collection which included a number of questions reviewing personal details, family details and education and at last number of enquiries reviewing the aforesaid issues viz. their health conditions, occupational morbidity, treatment seeking behavior, health expenditure and substance use.

\subsection{Construction of questionnaire}

Total of 450 questionnaire were prepared to find out the occupational morbidity, health risk and present health condition of brick kiln worker in the study area.

The data was drafted considering limitations from worker's side on priority and were finalized after pilot survey. While designing questionnaire worker's socio-economic and educational background were also took into consideration in order to provide them better and clear understanding about the questions asked. Questionnaire also consists of statistical and operational factors with a view point to provide the data a strong base. All questionnaires were filled through face to face interview.

\subsection{Data collection procedures}

In-depth interviews were conducted with workers of kiln, as a means to achieve the specific information about their job and associated morbidity. Data collection was conducted from November 2019 to May 2020 in ten different brick kilns in Azamgarh district of Uttar Pradesh. As the outbreak of Covid-19 pandemic it took me extra 2 months for data collection which was to be completed in March only. Data was collected best in the early morning before 8 a.m. or after 5 p.m. as workers were not allowed to be interviewed by the owners/managers in working hours.

\subsection{Data processing and analysis}

Data were analyzed using SPSS (Version 23) and STATA (Version 15). Descriptive statistics were used to summarize the data. Crosstabulations were done to get the frequency and percentages of the subcategories.

\section{Results}

\subsection{Sample characteristics}

During the study in brick kilns of Azamgarh district of Uttar Pradesh, 375 individuals out of 450 reported an illness episode within a year prior to the survey. These workers belonged largely from the state of Bihar, Madhya Pradesh and Uttar Pradesh. They all migrated from place of origin to place of destination in search of better opportunity. Schedule caste and Scheduled tribe represents $65.1 \%$ and $0.7 \%$ of the sample while $41.3 \%$ were illiterate and $4.4 \%$ found to be most qualified (up to 10 years of education). The brick kiln samples includes 10 brick kilns from Azamgarh area. Table 1 presents the characteristics from each brick kiln.

Table 1 presents the presents the bivariate analysis, both end of the age range reported less illness $28.5 \%$ from 24 to 35 and $16.9 \%$ from 51 to 65 , compared to middle age range $54.7 \%$ from 36 to 50 , irrespective of suffering from different disease. Brick kiln worker are basically classified in three categories i.e. molder, loader and firemen. Severity among molders is reported highest for the prevalence of eye disease $47.3 \%$, respiratory disease $56 \%$ and musculoskeletal disorder $88.7 \%$. Whereas, loaders are most effected from musculoskeletal disorder $88 \%$ followed by respiratory disease $49.3 \%$. Firemen reported highest prevalence for injury $27.3 \%$, respiratory disease $56 \%$ and eye disease $46.7 \%$. 
Table 1

Prevalence of various diseases among brick kiln workers by Background characteristics.

\begin{tabular}{|c|c|c|c|c|c|c|c|}
\hline Background Characteristics & Tuberculosis & Injury & Skin disease & Respiratory & Eye disease & Musculoskeletal disorder & Total \\
\hline Age & $\mathrm{N}(\%)$ & N (\%) & N (\%) & $\mathrm{N}(\%)$ & N (\%) & N (\%) & \\
\hline $24-35$ & $26(19.9)$ & $22(16.8)$ & $48(36.6)$ & $73(55.7)$ & $28(21.4)$ & $111(84.7)$ & 131 \\
\hline $36-50$ & $54(21.9)$ & $62(25.1)$ & $81(32.8)$ & $133(53.9)$ & $76(30.8)$ & $201(81.4)$ & 247 \\
\hline $51-65$ & $18(25)$ & $9(12.5)$ & $11(15.3)$ & $36(50)$ & $25(34.7)$ & $60(83.3)$ & 72 \\
\hline \multicolumn{8}{|l|}{ Years of Schooling } \\
\hline $0-4$ & $40(18.5)$ & $55(25.5)$ & 77 (35.7) & $121(56)$ & $61(28.2)$ & $190(88)$ & 216 \\
\hline $5-8$ & $54(26)$ & 33 (15.9) & $56(26.9)$ & $104(50)$ & $64(30.8)$ & $161(77.4)$ & 208 \\
\hline $9-10$ & $4(15.4)$ & $5(19.2)$ & $7(26.9)$ & $17(65.4)$ & $4(15.4)$ & $21(80.8)$ & 26 \\
\hline \multicolumn{8}{|l|}{ Substance use } \\
\hline Any addiction & $96(21.5)$ & $93(20.8)$ & $138(30.9)$ & $242(53.8)$ & $129(28.9)$ & $370(82.8)$ & 447 \\
\hline Smoking & $95(21.9)$ & $87(20.1)$ & 129 (29.7) & 234 (53.9) & $123(28.3)$ & $357(82.3)$ & 434 \\
\hline Drinking & $89(21.3)$ & $80(19.2)$ & $124(29.7)$ & $221(53)$ & $116(27.8)$ & $342(82)$ & 417 \\
\hline Chewing tobacco & $96(21.4)$ & $93(20.8)$ & $138(30.8)$ & $242(54)$ & $129(28.8)$ & $370(82.6)$ & 448 \\
\hline \multicolumn{8}{|l|}{ Years of working } \\
\hline $0-10$ & $67(22)$ & $62(20.3)$ & $100(32.8)$ & $158(51.8)$ & $77(25.3)$ & $253(83)$ & 305 \\
\hline $11-20$ & $28(22.1)$ & $26(20.5)$ & $35(27.6)$ & $75(59.1)$ & $45(35.4)$ & $103(81.1)$ & 127 \\
\hline $21-33$ & $3(16.7)$ & $5(27.8)$ & $5(27.8)$ & $9(50)$ & $7(38.9)$ & $16(88.9)$ & 18 \\
\hline \multicolumn{8}{|l|}{ Religion } \\
\hline Hindu & 78 (21.7) & $71(19.7)$ & $118(32.8)$ & $193(53.6)$ & $109(30.3)$ & $291(80.8)$ & 360 \\
\hline Muslim & $20(22.2)$ & $22(24.4)$ & $22(24.4)$ & $49(54.4)$ & $20(22.2)$ & $81(90)$ & 90 \\
\hline \multicolumn{8}{|l|}{ Caste } \\
\hline Scheduled Caste & $62(21.2)$ & $38(13)$ & $88(30)$ & $141(48.1)$ & $67(22.9)$ & $239(81.6)$ & 293 \\
\hline Scheduled Tribe & $1(33.3)$ & $0(0)$ & $0(0)$ & $3(100)$ & $2(66.7)$ & $2(66.7)$ & 3 \\
\hline Other Backward Caste & $35(22.7)$ & $55(35.7)$ & $52(33.8)$ & $98(63.6)$ & $60(39)$ & $131(85.1)$ & 154 \\
\hline \multicolumn{8}{|l|}{ Type of worker } \\
\hline Molder & $25(16.7)$ & $25(16.7)$ & $71(47.3)$ & $84(56)$ & $11(7.3)$ & $133(88.7)$ & 150 \\
\hline Loader & $34(22.7)$ & $27(18)$ & $35(23.3)$ & $74(49.3)$ & $48(32)$ & $132(88)$ & 150 \\
\hline Firemen & $39(26)$ & $41(27.3)$ & $34(22.7)$ & $84(56)$ & $70(46.7)$ & $107(71.3)$ & 150 \\
\hline Total & $98(21.8 \%)$ & $93(20.7 \%)$ & $140(31.1 \%)$ & $242(53.8 \%)$ & $129(28.7 \%)$ & $372(82.7 \%)$ & 450 \\
\hline
\end{tabular}

\subsection{Prevalence and treatment seeking with various occupational morbidity}

Total of 450 respondents, $82.7 \%$ suffered from musculoskeletal disorder, and $53.8 \%$ suffered from respiratory disease and a similar number of molders were suffering from aforementioned diseases (Table 1 ). More than $30 \%$ of workers suffered from eye disease and skin disease in 36-50 years of age category. More than $92 \%$ of workers reported alcohol consumption whereas, $96 \%$ reported smoking tobacco (Table 1). Prevalence of skin disease is found to be increasing with the increase in age, whereas, the same is found to be decreasing with the increase in education level. The results found that the prevalence of diseases shows a decreasing trend with the increase in years of working. This decreasing trend of disease with the increase in years of working may be counted as the result of less involvement of workers due to physical problems occurred in initial years of job. Skin disease is found to be most prevalent among molders constituting of $47.3 \%$, as they have to work bare had which lead to long hours of exposure of skin to water, sand, dust and mud. Whereas, injury is found to be highest (27.3\%) among firemen.

Table 2

Treatment seeking of various disease among Brick kiln workers by background characteristics.

\begin{tabular}{|c|c|c|c|c|c|c|c|}
\hline Background Characteristics & Tuberculosis & Injury & Skin disease & Respiratory & Eye disease & Musculoskeletal disorder & Total \\
\hline Age & N (\%) & N (\%) & N (\%) & N (\%) & N (\%) & N (\%) & \\
\hline $24-35$ & $19(73.1)$ & $9(40.9)$ & $39(81.3)$ & $51(69.9)$ & $23(82.1)$ & $90(81.1)$ & 131 \\
\hline $36-50$ & $29(53.7)$ & $35(56.5)$ & $62(76.5)$ & $106(79.7)$ & $54(71.1)$ & $168(83.6)$ & 247 \\
\hline $51-65$ & $11(61.1)$ & $4(44.4)$ & $5(45.5)$ & $28(77.8)$ & $18(72)$ & $43(71.7)$ & 72 \\
\hline \multicolumn{8}{|l|}{ Years of Schooling } \\
\hline $0-4$ & $24(60)$ & $22(40)$ & $55(71.4)$ & $85(70.3)$ & $41(67.2)$ & $146(76.8)$ & 216 \\
\hline $5-8$ & $33(61.1)$ & $25(75.8)$ & $46(82.1)$ & $88(84.6)$ & $52(81.3)$ & 135 (83.9) & 208 \\
\hline $9-10$ & $2(50)$ & $1(20)$ & $5(71.4)$ & $12(70.6)$ & $2(50)$ & $20(95.2)$ & 26 \\
\hline \multicolumn{8}{|l|}{ Marital Status } \\
\hline Married & $59(60.2)$ & $48(51.6)$ & $106(75.7)$ & $185(76.5)$ & $95(73.6)$ & 301 (80.9) & 450 \\
\hline \multicolumn{8}{|l|}{ Years of working } \\
\hline $0-10$ & $45(67.2)$ & $33(53.2)$ & $82(82)$ & $120(76)$ & 60 (77.9) & $213(84.2)$ & 305 \\
\hline $11-20$ & $12(42.9)$ & $12(46.2)$ & $21(60)$ & $56(74.7)$ & $33(73.3)$ & $75(72.8)$ & 127 \\
\hline $21-33$ & $2(66.7)$ & $3(60)$ & $3(60)$ & $9(100)$ & $2(28.6)$ & $13(81.3)$ & 18 \\
\hline \multicolumn{8}{|l|}{ Religion } \\
\hline Hindu & $48(61.5)$ & $30(42.3)$ & $20(17)$ & $140(72.5)$ & $76(69.7)$ & $225(77.3)$ & 360 \\
\hline Muslim & $11(55)$ & $18(81.8)$ & $14(63.6)$ & $45(91.8)$ & $19(95)$ & $76(93.8)$ & 90 \\
\hline \multicolumn{8}{|l|}{ Caste } \\
\hline Scheduled Caste & $37(59.7)$ & $18(47.4)$ & $70(79.6)$ & $106(75.2)$ & $53(79.1)$ & $184(77)$ & 293 \\
\hline Scheduled Tribe & $1(100)$ & $0(0)$ & & $3(100)$ & $2(100)$ & $0(0)$ & 3 \\
\hline Other Backward Caste & $21(60)$ & $30(54.6)$ & $36(69.2)$ & $76(77.6)$ & $40(66.67)$ & $117(89.3)$ & 154 \\
\hline \multicolumn{8}{|l|}{ Type of worker } \\
\hline Molder & $18(72)$ & $10(40)$ & $59(83.1)$ & $63(75)$ & $6(54.55)$ & $106(79.7)$ & 150 \\
\hline Loader & $17(50)$ & $19(70.4)$ & $18(51.4)$ & $67(90.5)$ & $42(87.5)$ & $108(81.8)$ & 150 \\
\hline Firemen & $24(61.5)$ & $19(46.3)$ & $29(85.3)$ & $55(65.5)$ & $47(67.14)$ & $87(81.3)$ & 150 \\
\hline Total & $59(60.2)$ & $48(51.6)$ & $106(75.7)$ & $185(76.4)$ & $95(73.6)$ & 301 (80.9) & 450 \\
\hline
\end{tabular}




\subsection{Utilization of outpatient care services}

In the study, 95\% workers were found suffering from occupational morbidity. Out of which $92.5 \%$ reported utilization of outpatient care, whereas, $7 \%$ of non-users stated, primary reason for not using health care services were, low financial support, unawareness of health centers, tight working hours. Lack of financial support and unavailability of health care centers nearby were self-explanatory for remaining foregone utilization. Table 2 describes association of workers and treatment seeking with levels of utilization of health care services. Multivariate analysis of patients using health care utilization at different level showed least utilization of public health care utilization $(20.3 \%)$ compared with private health care utilizations (54.2\%) for Tuberculosis (Fig. 1). Injury and other diseases like skin, eye and musculoskeletal disorder can be observed no utilization of public health care services. Meanwhile, private health care utilizations and pharmacy services are preferred for injury and other diseases like skin, eye and musculoskeletal disorder. Prevalence of musculoskeletal disorder is found to be highest (Table 1) among workers which justifies the high use of private health care utilization (87\%) in order to avail better treatment facility. Treatment seeking for respiratory (1\%) and musculoskeletal disorder (4.3\%) witnesses least utilization of home remedies. Pharmacy as a health care utilization is preferred by workers for the treatment of any disease. Highest utilization of pharmacy is observed among patients of skin disease, whereas, patients of musculoskeletal disorder have highest utilization of private health care compared to any disease.

\subsection{Reasons for non-utilization of health care services by symptomatic workers $(n=22)$}

The most common reason for not using health care services, stated by the workers was not considering their illness up to the extent that needs to be consulted with doctor at initial stage of morbidity. They considered to wait for few days, if they overcome illness symptoms and due to which most of the time, delay in treatment seeking results in increasing severity of disease. Added reasons by workers was unable to reach health centers while functioning hours due their own heavy work pressure. Other reasons stated for not using health care services were distant location of work place from health centers, unawareness of health centers and financial barriers.

\section{Discussion}

The study finds the higher percentage of workers suffering from skin disease (47\%), respiratory disease (56\%) and musculoskeletal disorder (88\%) among molders compared to other working class of loader and fireman. A significant association was found between aforementioned prevalence of disease and their treatment seeking behavior. Among molders $83 \%$ seek treatment for skin disease, $75 \%$ seek treatment for respiratory disease and $79 \%$ for musculoskeletal disorder. A very obvious reason for the high prevalence of respiratory disease among workers might be the living condition of workers. As workers stay in congested space without proper ventilation to out ventilate the cooking smoke and are directly exposed to smoke from cooking smoke as well as the outdoor pollution from the kiln dust. Both indoor and outdoor air pollution and overcrowding at place of stay have been reported as being the risk factor for respiratory diseases and tuberculosis. ${ }^{7}$ Findings from some of the other studies have also confirms the association of excessive smoking and high alcohol consumption with prevalence of respiratory disease and tuberculosis. Prevalence of chest symptoms and respiratory disease increases with increase in age as reported by former studies in south India. ${ }^{10}$

In this study, quit a considerable amount of treatment seeking has been observed among workers for their respective morbidity condition irrespective of odds like low income levels, remote location of stay and unawareness of health care centers. In spite of having lower wages workers from each category molder, loader and fireman are willing to avail health care facility. Even though, there are workers those who reported not using health care services are mostly ignorant about the illness symptoms. This may coincide with what Amartya Sen quoted as "perception bias" which means a tendency among most deprived to report less ill-health and underestimate their health problems irrespective of worker's financial power. ${ }^{9}$ Higher levels of perceived health have been reported in Kerala among the poor ${ }^{10,11}$ and some of the most deprived tribal populations. ${ }^{12}$ Some studies have suggested that inflating economy and increasing cost of health care services may be a leading factor for low income group not to consider them as ill to avail health care services. ${ }^{13}$ The under -reporting tendencies found in developing countries could result in underestimation of disparities in health care access. ${ }^{14}$

As, Fig. 1 presents a clear picture of high use of private outpatient

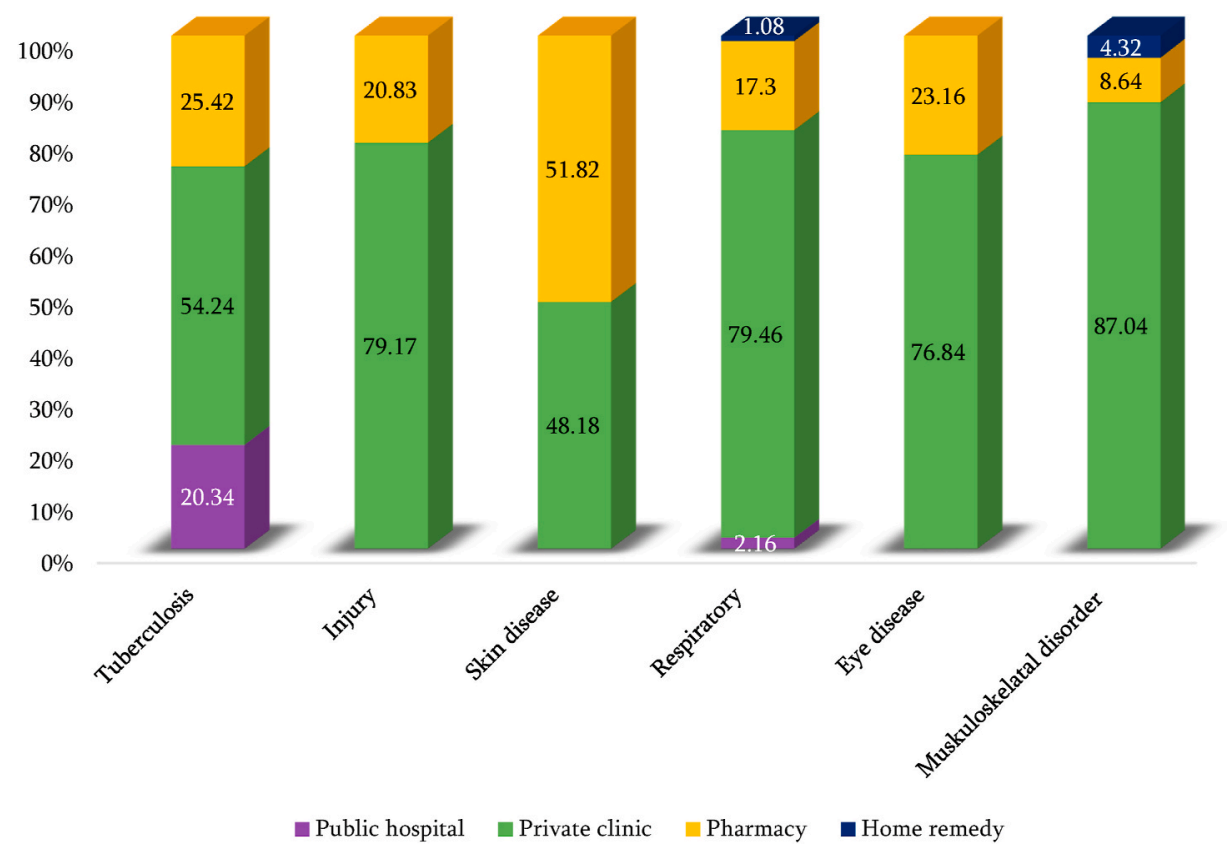

Fig. 1. Level of outpatient health care utilization among brick kiln workers for various disease. 
services among morbid workers. During the survey, workers utilizing private services justified their choice of private health services utilization with better availability with high quality of care compare with public services. These findings were reconfirmed from past studies in India. ${ }^{1,15,16}$ Some of other predominant reasons cited by workers from low income group were related to remote location of work place and time constraint due to their heavy work load and tight working schedule. This underlines the necessity for public institutions to respond to the needs of the poor by assuring services with a focus on effective availability and quality. ${ }^{17}$ Even having a general perception of private hospitals delivering better health facilities, there are some contraries. According to the study from Tamil Nadu stated that $60 \%$ of workers prefer to visit private hospitals. ${ }^{5}$ The private health care sector is heterogeneous in nature including a diversified facilities to patients from sophisticated services to small clinics operated by poorly qualified doctors or personnel. ${ }^{15}$ The low income group tends to be exposed more towards second-rated care, even in private care facilities. Due to lack of knowledge and unaware of trained practitioner, they get in touch with untrained and minimally qualified practitioner more often rather than consulting the trained one. ${ }^{18}$ As a matter of fact, well-off segments tends to use private care over public care in secondary and tertiary level facilities. ${ }^{19-22}$ A study revealed that preferring private cares over public care leads to $61 \%$ of labors incurring out-of-pocket expenditure among the $78.8 \%$ of migrant children. 6,8

\section{Conclusion}

The prevalence of occupational morbidity and treatment seeking behavior among brick kiln workers suggests that the situation still is in alarming condition. Though, the treatment seeking is delayed and quite low among the study group and that to they end up in consulting untrained and minimally qualified practitioners. Many of the labors were found highly ignorant about their ill symptoms, stating their ill condition not too serious to be administered. However, this relationship between labor and their medical condition is far from straight forward scenarios because worker's health condition and their utilization of health care facilities is determined by a range of multifaceted factors, including education, family size and responsibility, type of job and owner's employment policies. Due to low income, low educational status and skills, deprived workers are concentrated in inexpert, low grade and poorly paid jobs in the kilns where they are victimized by their employer and ill treatment regarding salary and wages were also observed.

\section{Declaration}

Ethical approval was obtained from Institute's Review Board (IRB) of International institute for population sciences, Mumbai.

\section{Funding}

This research did not receive any specific grants from funding agencies.

\section{Declaration of competing interest}

Authors declare that there is no conflict of interest.

\section{Acknowledgement}

None.

\section{References}

1 Dilip TR, Duggal R. Un met need for public health-care services in Mumbai, in dia. Asia-pacific population journal. 2004 Jun;19(2):27.

2 Kakade A, Damle SG, Bhavsar JP, Chatterjee V, Deb P. Combined effect of carbondioxide laser and neutral $2 \% \mathrm{NaF}$ on acid resistance of human tooth enamel. J Indian Soc Pedod Prev Dent. 1996 Mar 1;14(1):26-30.

3 Garg R. Improving the Performance of Reference Health Centre: A Case Study of Urban Health Center.

4 Garg CC, Karan AK. Health and millennium development goal 1: reducing out-ofpocket expenditures to reduce income poverty: evidence from India. Equity in AsiaPacific Health Systems. 2005 May.

5 Sudha G, Nirupa C, Rajasakthivel M, et al. Factors influencing the care-seeking behaviour of chest symptomatics: a community-based study involving rural and urban population in Tamil Nadu, South India. Trop Med Int Health. 2003 Apr;8(4): 336-341.

6 Kusuma YS, Babu BV. Migration and health: a systematic review on health and health care of internal migrants in India. Int J Health Plann Manag. 2018 Oct;33(4):775-793.

7 Thomas B, Suhadev M, Mani J, et al. Feasibility of an alcohol intervention programme for TB patients with alcohol use disorder (AUD)-a qualitative study from Chennai, South India. PloS One. 2011 Nov 21;6(11), e27752.

8 Charles N, Thomas B, Watson B, Sakthivel MR, Wares F. Care seeking behavior of chest symptomatics: a community based study done in South India after the implementation of the RNTCP. PloS One. 2010 Sep 20;5(9), e12379.

9 Sen A. Health: Perception versus Observation: Self Reported Morbidity Has Severe Limitations and Can Be Extremely Misleading.

10 Murray CJ, Chen LC. In search of a contemporary theory for understanding mortality change. Soc Sci Med. 1993 Jan 1;36(2):143-155.

11 Sen A. Objectivity and Position: Assessment of Health and Well-Being. Health and Social Change in International Perspective. 1994:115-128.

12 Mohindra KS, Haddad S, Narayana D, Aravind S. Health Profile of Kottathara Panchayat. Montreal: Université de Montréal; 2005 Dec 23.

13 Dilip TR. Understanding levels of morbidity and hospitalization in Kerala, India. Bull World Health Organ. 2002;80:746-751.

14 Castro-Leal F, Dayton J, Demery L. Public spending on health care in Africa: do the poor benefit? Bull World Health Organ. 2000;78:66-74.

15 Yesudian CA. Behaviour of the private sector in the health market of Bombay. Health Pol Plann. 1994 Mar 1;9(1):72-80.

16 Kunhikannan TP, Aravindan KP. Changes in the Health Status of Kerala, 1987-1997. Thiruvananthapuram: Kerala Research Programme on Local Level Development. Centre for Development Studies; 2000 Jun.

17 Maiga AS, Jacobs FA. Balanced scorecard, activity-based costing and company performance: an empirical analysis. J Manag Issues. 2003 Oct 1:283-301.

18 Levesque JF, Haddad S, Narayana D, Fournier P. Outpatient care utilization in urban Kerala, India. Health Pol Plann. 2006 Jul 1;21(4):289-301.

19 Pannarunothai S, Mills A. The poor pay more: health-related inequality in Thailand. Soc Sci Med. 1997 Jun 1;44(12):1781-1790.

20 Peters D, Yazbeck A, Ramana G, Sharma R, Pritchett L, Wagstaff A. Raising the Sights: Better Health Systems for India's Poor. vol. 173. The World Bank (Health, Nutrition, Population Sector Unit); 2001.

21 Zwi AB, Brugha R, Smith E. Private Health Care in Developing Countries: If it Is to Work, it Must Start from what Users Need.

22 Gupta I, Datta A. Inequities in Health and Health Care in India: Can the Poor Hope for a Respite. Delhi University: Institute of Economic Growth; 2003 Dec. 